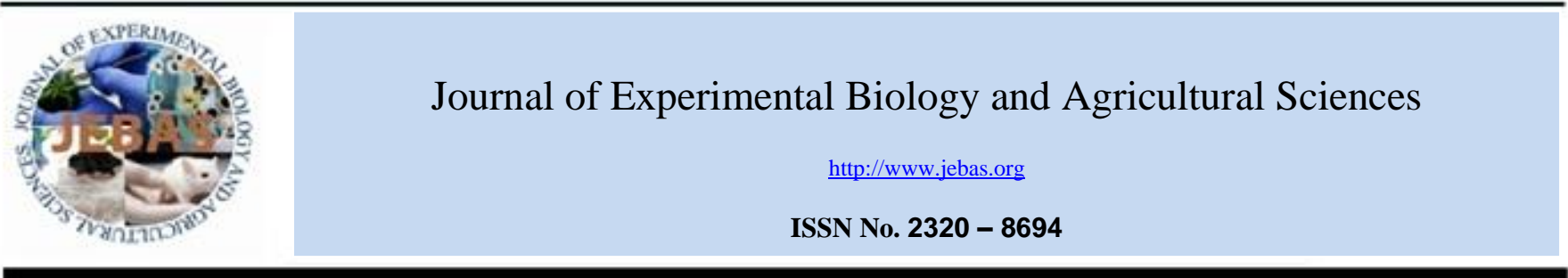

\title{
FORMULATION OF SELECTED SOY PRODUCTS FOR WOMEN'S HEALTH
}

\author{
Anitha $\mathrm{C}^{1^{*}}$, Vasantha Esther Rani ${ }^{2}$
}

${ }^{1}$ Department of Home Science, Seethalakshmi Ramaswami College (Autonomous), Tiruchirappalli, Tamilnadu, India
${ }^{2}$ Research Department of Home Science, Fatima College ((Autonomous), Madurai, Tamilnadu, India

Received - July 18, 2020; Revision - September 17, 2020; Accepted - December 08, 2020

Available Online - March 25, 2021

DOI: http://dx.doi.org/10.18006/2021.9(Spl-1-GCSGD_2020).S161.S168

\section{KEYWORDS}

Soy Bean

Tofu

Nutritive Value

Storage Study

\begin{abstract}
Soybean differs from other cereals and legumes by containing the highest amount of complete protein. Tofu, soy milk, soy meat are nonfermented products of soybean. Soy contains chemical compounds are unique because of its high concentration of isoflavones, a type of plant estrogen. Women entering the menopausal stage are recommended to consume soya bean because this plant estrogen would benefit them. The study aims to inculcate the consumption of soy products through standardized recipes. The popular soy milk product is Tofu. It is prepared by curdling fresh hot soy milk with a coagulant. On milling, soybean yielded a nutritious product called Soy flour, which is available in two types namely full-fat soy flour (FFSF) and defatted soy flour (DFSF). When the soybean oil is extracted, the byproduct called Soy Chunks is produced. In current study, soy products namely Tofu, Defatted Soy Flour, and Soy Chunks were used to standardize few recipes by incorporating them in commonly consumed recipes or using them wholly. Further, for this, Tofu with pasta and sandwich, Chunks in kurma and nuggets, DFSF with besan omelette, and cakes were incorporated and standardized. Along with this, organoleptic evaluations were carried out for the developed products and were standardized. The nutritive values for DFSF and storage stability of standardized cakes were also carried out.
\end{abstract}

* Corresponding author

E-mail: ceeanitha4@gmail.com (C. Anitha)

Peer review under responsibility of Journal of Experimental Biology and Agricultural Sciences.

Production and Hosting by Horizon Publisher India [HPI] (http://www.horizonpublisherindia.in/).

All rights reserved.
All the articles published by Journal of Experimental Biology and Agricultural Sciences are licensed under a Creative Commons Attribution-NonCommercial 4.0 International License Based on a work at www.jebas.org.

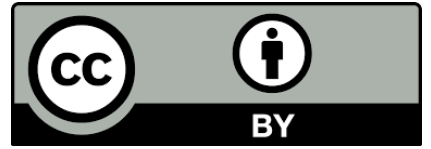




\section{Introduction}

Soybean (Glycine max) is known to be the world's widely cultivated and economically successful legume. Soybean is known as the "Golden bean", "Miracle crop", "Vegetable meat", and the "Cinderella crop" of the west because of its several uses. Soybean differs from other cereals and legumes by containing the highest amount of protein. Soybean has been known for long as versatile plant food that provides high-quality protein with only minimal saturated fat. Soybean is considered to be a good dietary source of protein (Singh et al., 2008). It is the only vegetarian food that contains all essential amino acids in the amounts needed for human health. It contains all the three-macro nutrients namely carbohydrate, protein, and fat required for good health and other nutrients like vitamins and minerals including calcium, folic acid, and iron. The soybean plant contains complete protein. Apart from the vegetable use of soybean, it is used by the oil industry and ranks first place in oil production. Soybean containing 43 percent protein and 20 percent oil has tremendous potential in the management of protein-calorie malnutrition among the ever increasing Indian population. Soy based food products are also suitable for diabetic patients as they contain less carbohydrate and low fat (Sharma et al., 2018). Soy protein is also good for people who are allergic to animal protein. Therefore, it is one of the most economical protein sources in the world for especially for those with lactose intolerance. Soy foods have several health benefits such as cancer prevention, cholesterol reduction, combating osteoporosis, and menopause regulation (Pabich \& Materska, 2019).

Soybean is rightly praised as being a treasure trove of many nutrients. In current day to day life, soy can be used in many ways such as Soybean, Soybean oil, Soy milk, Soy flour, Soy paneer (Tofu), Soy pappad, Soy nuts, Soy chocolates, and Soy chunks. Traditional soy foods are classified into two categories: nonfermented and fermented. The non-fermented soybean products are soy milk, tofu, tofu skin, soy meat alternatives. The fermented products include soy sauce, fermented bean paste, natto, sufu, miso, onchom, and tempeh (Liu, 2008; Singh, 2019). Tofu, a staple food in Asia for 2000 years, is known for its extraordinary nutritional benefits (Pal et al., 2019). Tofu is more popular among all the soy milk products. Tofu is prepared by coagulating the soy proteins in soy milk. It is also known as bean curd. The curd is processed and whey is discarded. The curd is an excellent source of calcium, iron, and a good source of protein (Oboh et al., 2007). Soy flour is an excellent source of protein, iron, and calcium. Defatted soy flour is also a good source of fiber. Defatted soy flour is a common form in which soybean can be incorporated in various food preparations. The soybean meal can be used to manufacture a product with meat like texture, known as textured vegetable protein. The textured vegetable protein is similar to cooked meat; hence it can be frozen, canned, or dehydrated like meat. It proved to be a fortune crop in India, in terms of edible oil production, export earnings, and rural prosperity.

Soybean contains phytosterols which are structurally similar to cholesterol and steroid hormones, which inhibit cholesterol absorption by blocking the absorption sites. Soy contains different types of chemicals such as phytoestrogens and isoflavones. Soy isoflavones are daidzein and genistein. Women entering menopause are recommended to consume soy because of the phytoestrogen content. As the natural production of oestrogen stops and symptoms may start. The phytoestrogens act as a weak oestrogen and they may help to relieve symptoms by boosting their levels (Desmawati \& Sulastri, 2019). Phytic acid content is high in soybean, which acts as an antioxidant and a chelating agent. Generally, people are aware of milk and its products but not soya and its products. Hence there is a need to create awareness and utilize these value added products. In this regard, in the current study selected soy products were used to standardize few recipes that can be applied in day-to-day cooking for consumption. These recipes aids in better health in the woman. Suitable recipes for each soy product namely Tofu, Defatted soy flour, and chunks were formulated. The study aims to enhance soy product consumption through normal diets for better health. Various recipes were formulated with soy products to ensure soy consumption at least in a meal.

\section{Materials and Methods}

\subsection{Collection of the sample}

Tofu, Defatted soy flour, and soy chunks were selected for the research purpose and they were collected from Sivakasi and Chennai, Tamilnadu, India. The other raw ingredients were collected from the local market. Analytical grade reagents and laboratory grade reagents were used for the biochemical analysis of the sample.

Soy milk is extracted from soybean by soaking $1 \mathrm{~kg}$ of soybean overnight and washed well before grinding. Then it was ground to a fine paste with water and milk is strained with a nut milk bag. Seven liters of soy milk was obtained from $1 \mathrm{~kg}$ of soybean. The soy milk was boiled and two grams of citric acid was added for every one liter of soy milk which means 14 grams of citric was used to ferment. The curdled part is filtered from soy whey water and washed with water. They were shaped and left pressed for 30 minutes and then cut into cakesto obtain tofu. The tofu was vaccum packed immediately. This tofu was used for product standardization whereas defatted soy flour and soy chunks were procured from the local market.

\subsection{Tofu products}

\subsubsection{Tofu with pasta}




\subsubsection{Ingredients}

Tofu - 25 gm; Pasta - 100 gm; Onion - 10 gm; Peas - 20 gm, French beans - 20 gm; Carrot - 20 gm; Green chilli - 5 gm; Oil - 1/2 Tsp.; Aniseeds - 1/4 Tsp; Spices - 1 number each (Cardamom, cloves, cinnamon, star anise)

\subsubsection{Method}

The pasta was precooked with excess water and strained. The Tofu was cut into cubes, the peas shelled, and french beans and carrots were chopped. In a saucepan, oil was heated, seasoned with aniseeds and spices, chopped onion and green chillies were added and sautéed it for few minutes. To this, vegetables and Tofu were added the cooked with the required salt and water. This was followed by the addition of pasta was stirred. Tofu with pasta was ready. It was then subjected to organoleptic evaluation.

\subsubsection{Tofu sandwich}

\subsubsection{Ingredients}

Tofu - 50gm; Onion - 50 gm; Tomato - 50 gm; Green Chilli - 5 gm; Oil - 1 Tsp.; Pepper powder - 1 Tsp; Tomato ketchup - 1 Tbsp; Butter - 1 Tbsp; Cheese slices - 1 (Optional); Salt - To taste ; Bread -4 slices.

\subsubsection{Method}

The tofu was shredded and kept aside. Onion, tomato, green chillies were finely chopped. Oil was heated in a saucepan, sautéed the chopped ingredients, pepper powder, and salt were added to the required taste. Finally, shredded tofu was added, garnished with coriander leaves, the stuffing was ready. The bread slices were greased with butter and tomato ketchup, the stuffing was spread, covered with another slice, and was toasted.

\subsection{Soy chunks products}

\subsubsection{Soy Nuggets}

\subsubsection{Ingredients}

Soy Chunks - 40 gm; Potato - 60 gm; Ginger Garlic paste - 4 gm; Red Chilli Powder - 4 gm; Garam Masala - 1 gm; Salt - As required; Corn Flour - 5 gm; Bread Crumps - 10 gm; Oil - To deep fry.

\subsubsection{Method}

Soy chunks were precooked for three to five minutes in boiling water and strained. They were then squeezed out to remove water and ground to crumbs. Potatoes were boiled, de-skinned, and mashed. Potatoes and soy chunk crumbs were mixed with the required amount of salt, chilli powder, and garam masala. They were rolled to balls and rolled in cornflour and bread crumbs and deep fried. It was then subjected to organoleptic evaluation.

\subsubsection{Soy chunks kurma}

\subsubsection{Ingredients}

Soy Chunks - 50 gm; Shallots - 15 gm; Garlic - 2 Pods; Tomato 25 gm; Aniseeds - 2 gm; Jeera - 5 gm; Pepper - 15 gm; Coriander Seeds - 15 gm; Coconut - 15 gm; Green Chillies - 5 gm; Curry leaves - A sprig; Coriander leaves - To garnish.

\subsubsection{Method}

Soy chunks were precooked for three to five minutes in boiling water and strained. Aniseeds, jeera, pepper, coriander seeds, coconut, and green chillies were sautéed in oil and ground to a paste. In a sauce pan, oil was heated, chopped shallots, tomatoes, garlic were sautéed and curry leaves were added. The ground paste, turmeric powder, and salt were added, boiled with precooked chunks. Garnished with coriander leaves and served. It was then subjected to organoleptic evaluation.

\subsection{Defatted soy flour incorporated products}

\subsubsection{DFSF omelette}

\subsubsection{Ingredients}

Besan flour - 50 gm; DFSF - 50 gm; Onion - 50 gm; Green chilli 5 gm; Chilli Powder - 5 gm; Turmeric Powder - 3 gm; Asafoetida a pinch; Coriander leaves - 5 gm; Oil - 2 tsp; Water and Salt - as required.

\subsubsection{Method}

Besan flour and DFSF were made into pouring consistency with water and turmeric powder, chilli powder, asafoetida, and salt were added. In a sauce pan with little oil, chopped onion and green chillies were sautéed. The flour batter was poured into a thin spread sprinkled with coriander leaves and cooked on either side. It was then subjected to organoleptic evaluation.

\subsubsection{DFSF incorporated Cake}

\subsubsection{Ingredients}

Refined wheat flour - 200 gm; Defatted Soy Flour - 40 gm; Baking powder - 1 Tsp; Hydrogenated vegetable oil - 250 gm; Sugar - 250 gm; Egg - 6 Nos. (Medium Size); Pineapple essence - 1 Tbsp; Tutty fruity -2 Tbsp. 
Table 1 Organoleptic Evaluation of Tofu Products

\begin{tabular}{|cccccccc|}
\hline \multirow{2}{*}{ Product } & Appearance & Flavour & Texture & Taste & Overall Acceptability & Overall Mean Score & Std. Deviation \\
& & & & & & & \\
\hline Tofu with Pasta & 3.4 & 3.6 & 3.8 & 3.6 & 3.5 & 3.58 & \pm 0.1483 \\
\hline Tofu Sandwich & 3.5 & 3.4 & 3.6 & 3.6 & 3.6 & 3.54 & \pm 0.0894 \\
\hline
\end{tabular}

Table 2 Organoleptic Evaluation of Soy Chunk Products

\begin{tabular}{|ccccccccc|}
\hline Product & Appearance & Flavour & Texture & Taste & Overall Acceptability & Overall Mean Score & Std. Deviation \\
\hline Soy Nuggets & 3.6 & 3.8 & 3.6 & 3.8 & 3.8 & 3.72 & \pm 0.1095 \\
\hline Soy Kurma & 3.5 & 3.6 & 3.6 & 3.6 & 3.6 & 3.58 & \pm 0.0447 \\
\hline
\end{tabular}

Table 3 Organoleptic Evaluation of DFSF Incorporated Soy Omelette

\begin{tabular}{|ccccccccc}
\hline Product & Appearance & Flavour & Texture & Taste & Overall Acceptability & Overall Mean Score & Std. Deviation \\
$\begin{array}{c}\text { Soy } \\
\text { Omelette }\end{array}$ & 3.8 & 3.8 & 3.6 & 3.8 & 3.8 & 3.76 & \pm 0.0894 \\
\hline
\end{tabular}

Table 4 Organoleptic Evaluation of DFSF Incorporated Cake at different levels of Incorporation

\begin{tabular}{|lcccccccc|}
\hline Product (Cake) & Appearance & Flavour & Texture & Taste & Overall Acceptability & Overall Mean Score & Std. Deviation \\
\hline 10\% DFSF (A) & 3.2 & 3.4 & 3.0 & 3.6 & 3.4 & 3.2 & \pm 0.2280 \\
\hline 20\% DFSF (B) & 3.4 & 3.3 & 3.1 & 3.8 & 3.6 & 3.4 & \pm 0.2702 \\
\hline $30 \%$ DFSF (C) & 3 & 2.8 & 2.6 & 2 & 3.1 & 2.7 & \pm 0.4358 \\
\hline
\end{tabular}

Table 5 Microbial analysis of DFSF Cake during Storage Period

\begin{tabular}{|cccccccc} 
& \multicolumn{2}{c}{$0^{\text {th }}$ Day } & \multicolumn{2}{c}{$7^{\text {th }}$ Day } & \multicolumn{2}{c}{$14^{\text {th }}$ Day } \\
Sample & Bacteria $\left(10^{-6}\right)$ & Fungi $\left(10^{-3}\right)$ & Bacteria $\left(10^{-6}\right)$ & Fungi $\left(10^{-3}\right)$ & Bacteria $\left(10^{-6}\right)$ & Fungi $\left(10^{-3}\right)$ \\
\hline P1 & - & - & 2 & 5 & 10 & 7 \\
\hline P2 & - & - & 1 & 3 & 4 & 6 \\
\hline
\end{tabular}

P1 - Polythene packed cake; P2 - Airtight plastic container packed cake

Table 6 Nutritive value of DFSF

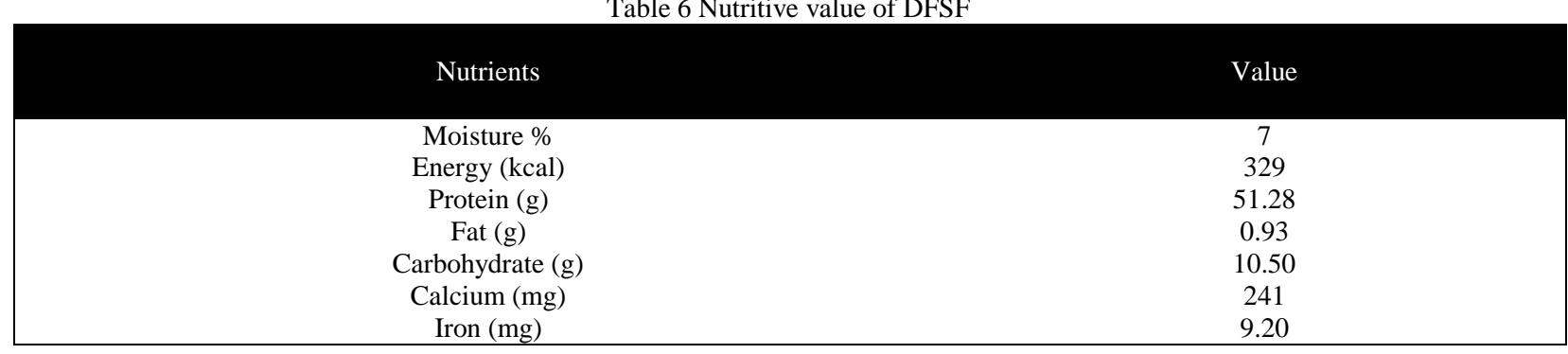

\subsubsection{Method}

Hydrogenated vegetable oil and sugar were creamed in a mixer until fluffy before adding the eggs. The defatted soy flour, wheat flour, and baking powder were thoroughly mixed together before folding into the creamed sugar and hydrogenated vegetable oil. Essence and garnishes were added. The batter was poured into a greased tray and baked at $200^{\circ} \mathrm{F}$ for $40 \mathrm{~min}$.
Cakes were formulated by incorporating defatted soy flour in different proportions $(10 \%, 20 \%$, and $30 \%)$ along with other ingredients. The three samples of cakes namely A (10\% DFSF incorporation), B (20\% DFSF incorporation), C (30\% DFSF incorporation) was developed, and one level of incorporation was formulated as per organoleptic evaluation. Defatted incorporated cakes were subjected for storage study and microbial analysis. 
The dearth of information for the formulated recipes has motivated the author to prepare the products either with soy products as a base or as incorporation or on proportions. Based on the overall acceptability the proportion has been standardized in the recipes. The consumption of soy products would enhance the health of women. The recipes ensure the consumption of soy products in a meal per day.

\subsection{Sensory evaluation of the developed products}

The developed products were subjected to the hedonic scale of sensory evaluation by a panel of judges. Panel members of 15 were selected and each individual was provided with a score card to assess the appearance such as colour, taste, flavour, consistency, and overall acceptability of the developed tofu products, Defatted soy flour incorporated products, and Soy chunks products.

The scorecard contained 4 points hedonic scale rating, viz., colour was appetizing (4) or appealing (3) or good (2) or bad (1), flavor was excellent (4) or good (3) or fair (2) or bad (1), consistency highly acceptable (4) or acceptable (3) or moderately acceptable (2) or not acceptable (1), taste was excellent (4) or good (3) or fair (2) or bad (1) and overall acceptability was very good (4) or good (3) or fair (2) or bad (1). Scientific methods of sensory analysis of foods have become of increasing importance in assessing the acceptability of food products.

When the quality of a food product is assessed using human sensory organs, the evaluation is said to be sensory or subjective or organoleptic. Sensory quality is a combination of different senses of perception used in choosing and eating food. Appearance, which can be judged by the eye (eg): Colour, Size, Shape, uniformity, and absence of defects are of first importance in food selection (Srilakshmi, 2018).

\section{Results}

\subsection{Standardization and sensory evaluation}

\subsubsection{Tofu products}

\subsubsection{Tofu with pasta}

Table 1 shows the sensory evaluation scores of the formulated tofu with pasta and tofu sandwich. The organoleptic characteristics were evaluated using 15 judging panels and four points hedonic rating scale. The sensory attributes of tofu with pasta were as following - appearance was appealing (3.4), flavour was excellent (3.6), texture was highly acceptable (3.8), taste was excellent (3.6) and the overall acceptability was very good (3.5). Two grams of protein will be provided when $25 \mathrm{gm}$ tofu is consumed.

\subsubsection{Tofu sandwich}

The organoleptic characteristics for the formulated tofu sandwich show that the appearance was appetizing (3.5), flavour was good (3.4), texture was highly acceptable (3.6), taste was excellent (3.6) and the overall acceptability was very good (3.6) and it was standardized. Four grams of protein will be provided when $50 \mathrm{gm}$ of tofu sandwich is consumed (Table 1).

\subsubsection{Soy chunks products}

\subsubsection{Soy nuggets}

The organoleptic characteristics for formulated soy nuggets in table 2 show that colour was appetizing (3.6), flavour was excellent (3.8), texture was highly acceptable (3.8), taste was excellent (3.6) and overall acceptability was very good (3.8) and it was standardized. Twenty one grams of protein will be provided when 40 grams of soy chunks are consumed (Table 2).

\subsubsection{Soy chunks kurma}

The organoleptic characteristics for the formulated soy kurma show that colour was appetizing (3.5), flavour was excellent (3.6), consistency was highly acceptable (3.6), taste was excellent (3.6) and the overall acceptability was very good (3.6) and it was standardized (Table 2). Twenty six grams of protein will be provided when 50 grams of soy chunks are consumed.

\subsubsection{Defatted soy flour incorporated products}

\subsubsection{Soy omelette}

The organoleptic characteristics for the formulated soy omelette (table 3) show that colour was appetizing (3.8), flavour was excellent (3.8), texture was highly acceptable (3.6), taste was excellent (3.8) and the overall acceptability was very good (3.8) and it was standardized. Twenty five grams of protein will be provided when 50grams of defatted soy flour were consumed (Table 3).

\subsubsection{DFSF incorporated cake}

Cakes were formulated by incorporating DFSF in different proportions $(10 \%, 20 \%, 30 \%)$. The developed cakes were subjected to the hedonic scale of sensory evaluation with 15 trained judges. Each individual was given a scorecard to assess the appearance such as colour, flavour, texture, taste, and overall acceptability of the developed cakes were evaluated and standardized.

Table 4 shows the organoleptic evaluation of DFSF (10\%, 20\%, $30 \%$ ) cakes. The overall mean scores of 10 percent, 20 percent, and 30 percent incorporation were $3.2,3.4$, and 2.7 respectively. 
Among the three formulations, 20 percent incorporation level was highly accepted and it was standardized. They were packed in polythene packet (250 gauges) $\left(\mathrm{P}_{1}\right)$ and airtight plastic container $\left(\mathrm{P}_{2}\right)$ to study the storage stability.

On storage, a slight decrease in all the quality attributes were observed due to a change in texture, flavour, and taste in both the packaging material. On 0 day of storage (Table 5) there was no bacteria and fungi growth in both P1 and P2. On 7th and 14th day of storage, there was an increase in bacterial and fungal growth in the cakes packed in P1and P2. The cake was highly acceptable on the 1 st day. The cakes packed in air-tight plastic containers were good than the cakes packed in polythene packs.

Nutritive value of DFSF showed 7 percent of moisture content, $329 \mathrm{kcal}$ of energy, $51.28 \mathrm{~g}$ of protein, $0.93 \mathrm{~g}$ of fat, $10.50 \mathrm{~g}$ of carbohydrate, $241 \mathrm{mg}$ of calcium, and $9.20 \mathrm{mg}$ of iron in Table 6 . The nutritive content of the DFSF cake (20\%) was analyzed during the storage period. It exhibited a slight decrease in the carbohydrate, protein, and fat content packed in P1and P2 respectively. The iron and calcium contents did not exhibit any change in storage.

\section{Discussion}

Vegetarians prefer soy and soy foods as their nutritional solutions because of their high protein content and functional property in the production of milk substitutes and meat like similarity. Hence soy products were taken for the study. Soy protein can be used as a source of high-quality protein. Soy proteins provide the necessary essential amino acids for physical and muscular development (Carbone \& Pasiakos, 2019).

The phytoestrogens and bioactive compounds in soy namely isoflavones are polyphenols having estrogenic properties. These being rich in soy bean have remarkable characteristics which are noteworthy for vegetarians (Rizzo \&Baroni, 2018). Soy bean meal can be used to manufacture a product with meat like texture, known as textured vegetable protein. The vegetable protein is extracted by the addition of an alkali and fibers are formed by extruding the protein through fine nozzles or spinerettes. The fibers are combined with fat, a protein binder along with colours and flavours. As the product is similar to cooked meat, it can be frozen, canned, or dehydrated (Anon, 2019).

Tofu is rich in B-vitamins and protein of high biological value. In vegetarian recipes, Tofu is used as a substitute for meat. It also contains nine essential amino acids and is also free of saturated fat or cholesterol. Further, Rizzo \& Baroni (2018) also suggested that Tofu is rich in isoflavones, which will reduce the risk of osteoporosis. Tofu was introduced in Japan in the 8th century, where it was originally known as "Okabe", but was not called "tofu" until the 15 th century. While serving as a traditionally made dish, tofu did not gain its great widespread popularity in the west until it was recognized as healthier foods. First, it was gaining more widespread attention during the 1960s, and skyrocketing in popularity ever since research has begun to reveal many significant benefits, this nutrient rich, plant-based food can provide.

In the present study, tofu was incorporated with the normally planned meals such as cereal based pasta and bread sandwich. The overall acceptability was very good for the formulated tofu products namely tofu with pasta and tofu sandwich with 3.5 and 3.6 scores in sensory evaluation. Diet rich in soy protein has many health benefits that are unique to women's needs.A diet rich in soy protein may alleviate certain symptoms associated with menopause.

It helps to reduce the risk of breast cancer, promoting heart health, and maintain bone health. It is a good source of fiber, iron, calcium, zinc, and B vitamins (Dudek 2001).

The effect of substituting 50 percent of the pulse fraction of Indian recipes with defatted soybean flour on quality and the nutritive value was found to have higher carbohydrate, calorie, calcium, phosphorus, iron, and protein contents (Kaveri \& Bindhu, 2004). Hence defatted soy flour was incorporated with besan flour and refined wheat flour to develop soy omelette and soy cakes. Similarly, Chokkammal \& Chitra (1999) also incorporated DFSF with bakery items namely bread, sweet bun, vegetable puffs, biscuits, teacake, and soymilk-incorporated desserts. Bakery products like biscuits formulated with soy were supplemented with B-complex and iron tablets in the diet of school children for 4 months resulted in a reduction of signs and symptoms of nutrient deficiencies in children.

In the present study different proportions $(10 \%, 20 \%, 30 \%)$ of DFSF incorporated cakes were prepared. The quality attributes were found to be high at 20 percent incorporation and were standardized. Polythene packet (250 gauges) and airtight plastic container were used as packaging material to study the storage stability. On storage, the DFSF cake exhibited a slight decrease in the carbohydrate, protein, and fat content when packed P1and P2 respectively. The Iron and Calcium contents did not show any change in storage. On storage, a slight decrease in all the quality attributes were observed on 7 th and 14th day of storage. There was an increase in bacterial and fungal growth in the cakes packed in P1and P2. It was concluded that the DFSF cake stored in a polythene packet and the airtight container was found to be acceptable.

Bakery product production is increasing and becoming popular in India, during the last 10 years. Soy flour does many things in bakery foods like increasing the protein content of a baked food 
(Anon 2019). Further, Hoover (1979) stated that technology for the utilization of soy products in bakery foods is well established and reasonably simple. The baking industry can realize the benefits of soy protein. Soy flour helps to reduce the glycemic index of all baked food and provides a way to improve blood sugar control, reduce carbohydrate load improves foods protein content (Blair et al., 2006)

In the present study, soy chunks were used with standardizing suitable recipes incorporated and developed with the same. The products formulated with soy chunks namely soy nuggets and soy kurma had 3.8 and 3.6 overall acceptability score on sensory evaluation. Phytoestrogens are acting like synthetic estrogen which helps women to protect themselves from bone loss and maintain a healthy heart (Wardlaw, 2000). Soy protein balances the calcium by influencing the bone in postmenopausal women. It is significant for women who are not receiving hormone replacement therapy (Bhathena \& Velasquez 2002).

Soy products mainly provide protein, energy, and vitamins, protect the heart, fight cancer, improve mood and mental health, improve mental state, reduce the symptoms of osteoporosis, managing diabetes, alleviate menopause problems, reduce Gastro-intestinal disorders (Itapu, 2000)

\section{Conclusion}

Soybean is an excellent health food and contains about 40 percent good quality protein and reasonable amounts of minerals and vitamins. Soy protein in the diet may alleviate certain menopausal symptoms in women. It also reduces the risk of breast cancer. Bone health will be maintained well and it promotes heart health also. To conclude the formulation of selected soy-based recipes for women's health will aid in combating the menopausal symptoms through their diet. The products were planned in such a way that women can consume soy atdifferent timing in different forms to ensure the intake of isoflavones through soy to overcome her symptoms.

\section{Conflict of interest}

The authors declare that they have no conflict of interest.

\section{References}

Anon (2016) History of modern soy protein ingredients - isolates, concentrates, and textured soy protein products. Journal of the American Oil Chemists Society 56(3):20.

Bhathena SJ, Velasquez MT (2002) Beneficial role of dietary phytoestrogens in obesity and diabetes. American Journal of Clinical Nutrition 76: 1191-201.
Blair RM, Henley EC, Tabor A (2006) Soy foods have low glycemic and insulin response indices in normal weight subjects. Nutrition Journal 5(35).

Carbone JW, Pasiakos SM (2019) Dietary protein and muscle mass: Translating science to application and health benefit. Nutrients 11(5): 1136. DOI: 10.3390/nu11051136.

Chokkammal S, Chitra R (1999) Formulation of defatted soy flour and soymilk based recipes and impact of supplementation of soy biscuits to selected rural school children. Abstract Food tech '06. New Horizon in Processing of Value Added Convenience Food. 22.

Desmawati D, Sulastri D (2019) Phytoestrogens and their health effect. Open Access Macedonian Journal of Medical Sciences 7(3): 495-499.

Dudek SG (2001) Nutrition Essentials for Nursing Practice. 4th ed. Philadelphia: Lippincott Williams and Wilkins.

Hoover W (1979) Use of soy proteins in baked foods. Journal of the American Oil Chemists Society 56(3):20.

Itapu (2000) Soyflour in Bakery products, Human Nutrition, American Soybean Association, New Delhi 1-8.

Kaveri R, Bindhu NVU (2004) Value addition and acceptability of Selected Indian recipes with whole and defatted soyaflour. Indian Journal of Nutrition Dietitics 41(10):426-436.

Liu K (2008) Food Use of Whole Soybeans. Biology. DOI: 10.1016/B978-1-893997-64-6.50017-2.

Oboh G, Ekperigin MM, Akindahunsi AA (2007) Coagulant modulates the hypocholesterolemic effect of Tofu (coagulated soymilk). Journal of Medicinal Food 10(2):388-91.

Pabich M, Materska M (2019) Biological Effect of Soy Isoflavones in the Prevention of Civilization Diseases. Nutrients 11(7): 1660.

Pal M, Devrani M, Ayele Y (2019) Tofu: A popular food with high nutritional and health benefits. Ingredients \& Additives, Food \& Beverages Processing 54-55.

Rizzo G, Baroni L (2018) Soy, Soy Foods and Their Role in Vegetarian Diets. Nutrients 10(1): 43

Sharma B, Jagdish Patidar S, Tripaty Pachaury DR (2018) Assessment of supplementation of Soy-Poha Ladoo for prevention of malnutrition in rural area of Ratlam district. India. International 
Journal of Current Microbiology and Applied Sciences 7(12): 393- Soybean, A Miracle Bean ASA - International Marketing. 396.

Available

from:https://pfndai.org/Document/Resource/Resourses_Nutrition/

Singh CB (2019) Trends and Challenges of Indian Bakery Industry, Available from :https://www.nuffoodsspectrum.in/blog/37/5221/trendsand-challenges-of-indian bakery-industry.

Resources-N-soybean.pdf

Srilakshmi B (2018) Sensory evaluation. Food Science. New Age International Publishers, New Delhi.

Singh P, Kumar, R, Sabapathy SN, Bawa AS (2008) Functional and edible uses of soy protein products. Comprehensive reviews in food science and food safety 7(1):14-28.

Wardlaw GM (2000) Contemporary Nutrition. 4th ed. Boston: McGraw Hill. 